\title{
ANALISIS PENDAPATAN PADA USAHA AYAM PETELUR "SUYATNO FARM" DI DESA KALISIDI KECAMATAN, UNGARAN BARAT, KABUPATEN SEMARANG
}

(The Income Analysis of Chicken Laying Business At Suyatno Farm In Kalisidi Village, West Ungaran District, Semarang Regency)

\author{
Nussifa, N. ${ }^{1}$, W. Roessali ${ }^{2}$ dan H. Setyawan ${ }^{3}$ \\ 1) Mahasiswa Fakultas Peternakan Dan Pertanian Universitas Diponegoro \\ Kampus drh. Soejono Koesoemowardojo, Jl. Prof. H. Soedarto, SH Tembalang Semarang \\ 50275 \\ E-mail : nurulayuandini@gmail.com

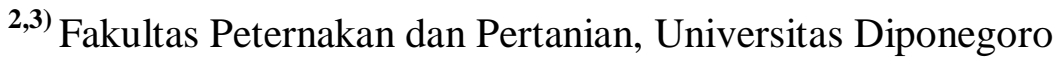 \\ Kampus drh. R. Soejono Kusumowardojo Tembalang, Semarang 50275
}

Diterima : 25 Januari $2016 \quad$ Disetujui : 25 Juni 2016

\begin{abstract}
A study aims to asses the amount of income the business laying Suyatno Farm. This research was conducted at the laying farm Suyatno Farm in the Kalisidi Village, West Ungaran District, Semarang regency. Methods of data collection in this study using interviews and observation (observation). Primary data is data "Time Series" for 3-year production period 2011, 2012 and 2013. The quantitative analysis was tested using a onesample t-test, to compare the income of the minimum salary Semarang District (MSD). Based on the results of this study concluded that the cost of production Suyatno Farm during 2011-2013 reached a value of $R p$ 5,684,736,253; $R p$ 6,522,332,735; $R p$ 7,117,395,201. Total revenues in 2011 reached $R p$ 7,045,817,205, an increase of $5.80 \%$ ie to $R p$ 7,454,136,027 in 2012 and increased by 8.28\% to $R p$ 8,071,660,113 in 2013. Net income for the business of laying hens Suyatno Farm in 2011-2012 decreased by 30.38\% and in 2012-2013 increased by 2.28\%. Based on one sample t-test that the ratio of income per month with a minimum salary District (MSD) Semarang significantly different $(P<0.05)$. The conclusions obtained from this study was the increase in the cost of production and receipts, but a decline in income in 2011-2012 and the increase in 20122013. Monthly profit farms Suyatno Farm is higher than the MSD Semarang regency, so it deserves to be operated in the district of Semarang.
\end{abstract}

Keywords : layer, revenue, net income

\begin{abstract}
ABSTRAK
Sebuah penelitian bertujuan untuk mengkaji besarnya pendapatan usaha pada ayam petelur Suyatno Farm. Penelitian ini dilaksanakan di Peternakan ayam petelur Suyatno Farm di Desa Kalisidi, Kecamatan Ungaran Barat, Kabupaten Semarang. Metode pengumpulan data dalam penelitian ini menggunakan metode wawancara dan observasi (pengamatan). Jenis data dikumpulkan adalah data primer dan data sekunder. Data primer berupa data "Time Series" selama 3 tahun periode produksi 2011, 2012 dan 2013. Analisis kuantitatif diuji menggunakan one sample t-test, untuk membandingkan pendapatan
\end{abstract}


terhadap upah minimum Kabupaten Semarang (UMK). Berdasarkan hasil penelitian dapat disimpulkan bahwa biaya produksi Suyatno Farm selama 2011-2013 mencapai nilai Rp 5.684.736.253; Rp 6.522.332.735; Rp 7.117.395.201. Total penerimaan pada tahun 2011 mencapai Rp 7.045.817.205, mengalami peningkatan sebesar 5,80\% yaitu menjadi Rp 7.454.136.027 pada tahun 2012 dan meningkat sebesar 8,28\% menjadi Rp 8.071.660.113 pada tahun 2013. Pendapatan bersih usaha ayam petelur Suyatno Farm pada tahun 20112012 mengalami penurunan sebesar 30,38\% dan pada 2012-2013 meningkat sebesar $2,28 \%$. Berdasarkan one sample t-test diketahui bahwa perbandingan pendapatan bersih per bulan dengan upah minimum Kabupaten (UMK) Semarang berbeda nyata $(\mathrm{P}<0,05)$. Simpulan yang diperoleh dari penelitian ini adalah terjadinya peningkatan untuk biaya produksi dan penerimaan, akan tetapi terjadi penurunan pendapatan bersih pada tahun 2011-2012 dan kenaikan pada tahun 2012-2013. Keuntungan perbulan Suyatno Farm lebih tinggi dibanding UMK Kabupaten Semarang, sehingga usaha peternakan layak untuk dijalankan di Kabupaten Semarang.

Kata kunci : ayam petelur, penerimaan, pendapatan bersih

\section{PENDAHULUAN}

Peternakan ayam petelur merupakan sub sektor pertanian yang potensial untuk menjadi sumber kekuatan perekonomian di Indonesia, yang selama ini selalu terpusat pada industri pemenuhan pangan melalui ayam. Permintaan telur yang meningkat pada tahun 2013-2014 di Provinsi Jawa Tengah sebesar 5\% menjadi indikator penting, bahwa industri peternakan ayam petelur akan semakin berkembang dan modern. Keadaan tersebut harus didukung melalui sistem manajemen kelola yang baik dan peningkatan sumber daya peralatan yang memadai, sehingga kedepan hasil produksi akan meningkatkan kesejahteraan peternak.

Salah satu wilayah di Provinsi Jawa Tengah yang mempunyai potensi dan keuntungan geografis untuk industri peternakan ayam petelur adalah Kabupaten Semarang. Berdasarkan perhitungan statistik pada tahun 2013, produksi telur ayam ras di Kabupaten Semarang sebesar $17.766 .701 \mathrm{~kg}$. Tingginya produksi usaha ayam petelur di Kabupaten Semarang tersebut berkontribusi penting dalam pendapatan asli daerah dan menjadi sumber pendapatan utama bagi masyarakat setempat. Faktor-faktor produksi dalam industri peternakan ayam petelur diantaranya adalah pembelian ayam, biaya listrik (Dewanti dan Sihombing, 2012), kepadatan kandang dan konsumsi pakan (Fenita, 2011). Selain itu diperlukan manajemen yang baik untuk mencapai tingkat keuntungan yang optimal. Analisis kelayakan suatu usaha diperlukan untuk menilai apakah usaha ini layak atau tidak untuk dikembangkan di masa yang akan datang (Mulyani dan Atriani, 2013).

Penelitian ini bertujuan untuk mengkaji besarnya pendapatan usaha pada peternakan ayam petelur Suyatno Farm, melakukan analisis perkembangan kinerja usaha tiap tahun pada peternakan ayam petelur Suyatno Farm dan membandingkan kelayakan usaha peternakan ayam petelur terhadap upah minimum di wilayah Kabupaten Semarang. Penelitian ini diharapkan dapat memberikan informasi kepada masyarakat terutama pemilik peternakan ayam petelur "Suyatno Farm" mengenai kebutuhan modal kerja yang cukup dan tata kelola manajemen yang benar, sehingga dapat digunakan sebagai acuan untuk memajukan usahanya pada 
masa yang akan datang yang ditinjau dari segi pendapatan.

\section{MATERI DAN METODE}

\section{Materi}

Penelitian ini dilaksanakan di Peternakan ayam petelur Suyatno Farm di Desa Kalisidi, Kecamatan Ungaran Barat, Kabupaten Semarang. Responden dari pengamatan ini adalah karyawan perusahaan peternakan ayam petelur Suyatno Farm.

\section{Metode}

Metode pengumpulan data dalam penelitian ini menggunakan metode wawancara dan observasi (pengamatan). Jenis data dikumpulkan adalah data primer dan data sekunder. Data primer diperoleh melalui pengamatan langsung dan hasil wawancara dengan menggunakan kuesioner mengenai aspek teknis dan keuangan. Data primer berupa data "Time Series" selama 3 tahun periode produksi 2011, 2012 dan 2013. Data yang sudah terkumpul selanjutnya diedit, ditabulasi dan dianalisis secara deskriptif dan kuantitatif. Analisis kuantitatif diuji menggunakan one sample $t$ test, untuk membandingkan pendapatan terhadap upah minimum Kabupaten
Semarang (UMK). Untuk mengkaji kelayakan usaha digunakan analisis pendapatan melalui tingkat profitabilitas dan return cost ratio (R/C).

\section{HASIL DAN PEMBAHASAN}

\section{Kondisi Peternakan}

Lokasi usaha peternakan ayam petelur Suyatno Farm terletak di Desa Kalisidi, Kecamatan Ungaran Barat, Kabupaten Ungaran. Peternakan ayam petelur Suyatno Farm terletak pada kemiringan 25-45\% dengan curah hujan rata-rata tahunan mencapai $1979 \mathrm{~mm} /$ tahun dan suhu ratarata harian berkisar $23-26{ }^{\circ} \mathrm{C}$. Peternakan Suyatno Farm memiliki jumlah ternak 33178 ekor ayam dengan jumlah kandang sebanyak 18 kandang dengan masingmasing kandang di isi 2000 ekor ayam. Lokasi peternakan Suyatno Farm berjarak \pm 250 meter dari daerah pemukiman penduduk setempat, dengan jarak tersebut lokasi peternakan Suyatno Farm sudah sesuai dengan dengan Permentan No. 31/Permentan/OT.140/2/2014 bahwa jarak lokasi peternakan dengan pemukiman penduduk minimal 25 meter. Peternakan Suyatno Farm mempunyai 18 buah kandang dengan sistem kandang baterai berbahan kawat.

Tabel 1. Performa Produksi Ayam Petelur Tahun 2011-2013.

\begin{tabular}{lcccc}
\hline \hline \multirow{2}{*}{ Keterangan } & \multicolumn{3}{c}{ Tahun } & \multirow{2}{*}{ Pertumbuhan (\%) } \\
\cline { 2 - 4 } & 2011 & 2012 & 2013 & \\
\hline Populasi (ekor) & 31578 & 32046 & 32483 & 0,87 \\
Mortalitas (\%) & 1,29 & 3,23 & 2,14 & 0,85 \\
Jumlahpakan (kg) & 1222583 & 1270075 & 1260600 & 3,11 \\
JumlahTelur (Kg) & 576324 & 586560 & 585425 & 1,58 \\
Hen Day Production (\%) & 80 & 80,6 & 83,4 & 3,40 \\
Feed Convertion Ratio & 2,14 & 2,08 & 2,09 & $-0,05$ \\
\hline
\end{tabular}


Berdasarkan Tabel 1. di atas Performa produksi rata-rata aspek persentase mortalitas dan FCR selama tiga tahun berturut-turut adalah $(1,29 ; 3,23 ; 2,14 \%)$ dan $(2,14 ; 2,08 ; 2,09)$. Jumlah pakan yang dihabiskan selama tiga tahun berturut-turut mencapai 1222583, 1270075 dan 1260600 $\mathrm{kg}$. Nilai hen day production ayam petelur peternakan Suyatno Farm selama kurun waktu tiga tahun berturut-turut mencapai 80; 80,6 dan 83,4. Berdasarkan FCR tahunan yang mencapai 2,14; 2,08 dan 2,09, menunjukkan bahwa efisiensi pakan yang dibutuhkan untuk memproduksi telur. Hal ini sesuai dengan Management Guide yang di terbitkan oleh Isa Brown (2011), bahwa FCR ayam petelur pada awal bertelur hingga afkir (90 minggu) mencapai 2,092,20. Rasyaf (2009) menyatakan bahwa nilai FCR yang kecil menunjukkan bahwa performa yang dicapai memuaskan karena jumlah pakan yang dikonsumsi untuk digunakan untuk memproduksi telur yang berarti penggunaan pakannya efisien.

\section{Pendapatan}

Berdasarkan data pada Tabel 2. diketahui bahwa pendapatan bersih tersebut ada setelah pendapatan dikurangi dengan pajak. Pendapatan untuk tiap bulan pada Suyatno Farm setelah pajak pada tahun 2011-2013 mencapai Rp 76.537.718; Rp 53.285.178 dan $\mathrm{Rp}$ 54.501.849, angka tersebut lebih tinggi dibanding Upah Minimum Kabupaten (UMK) Semarang sebesar Rp 1.051.000. Laju perubahan pendapatan perbulan peternakan Suyatno Farm pada tahun 2011-2012 mengalami penurunan sebesar $30,38 \%$ sedangkan pada tahun 2012-2013 mengalami peningkatan sebesar $2,28 \%$. Penurunan pendapatan pada tahun 2011-2012 dikarenakan terjadinya kenaikan biaya produksi sebesar Rp 837.596.482, yang disumbang terbesar pada kenaikan pembelian pakan dari Rp 3100-Rp 3600 dengan nilai total $\mathrm{Rp} 782.263 .397$ dan terjadi penurunan total penerimaan disebabkan produksi yang menurun karena pada tahun 2012 sebgian ayam terserang penyakit ND (New Castle Disease) sehingga banyak ayam yang mati. Peningkatan pendapatan pada tahun 20122013 sebesar 2,28\% disumbang karena adanya peningkatan total penerimaan dibanding tahun 2011-2012 sebesar Rp 617.524.087 dan menurunnya biaya produksi dibanding tahun 2011-2012 sebesar Rp 595.062.466. Berdasarkan analisis return cost ratio dan profitabilitas selama tiga tahun berturut-turut mencapai $(1,24 ; 1,14 ; 1,13)$ dan $(16,16 ; 9,80 ; 9,19)$. Dengan nilai $\mathrm{R} / \mathrm{C}$ yang lebih dari 1 dan profitabilitas yang lebih tinggi dari suku bunga deposito bank sebesar 5,5\%, maka usaha ayam petelur milik bapak Suyatno layak untuk dijalankan dan menguntungkan.

Tabel 2. Pendapatan Usaha Tahun 2011-2013.

\begin{tabular}{|c|c|c|c|}
\hline Uraian & Tahun 2011 & Tahun 2012 & Tahun 2013 \\
\hline Biaya Produksi & 5.684 .736 .253 & 6.522.332.735 & 7.117.395.201 \\
\hline Penerimaan & 7.045.817.205 & 7.454.136.027 & 8.071 .660 .113 \\
\hline Pendapatan Sebelum Pajak (EBT) & 1.361 .080 .953 & 931.803 .292 & 954.264 .913 \\
\hline Pajak Penghasilan & 442.628 .333 & 292.381 .152 & 300.242 .720 \\
\hline Pendapatan Setelah Pajak (EAT) & 918.452 .619 & 639.422 .140 & 654.022 .193 \\
\hline Pendapatan per Bulan & 76.537 .718 & 53.285 .178 & 54.501 .849 \\
\hline
\end{tabular}


Hasil penelitian ini menunjukkan bahwa semakin meningkatnya populasi ayam petelur yang dibudidayakan maka semakin tinggi pula pendapatan yang diperoleh peternak. Hasil ini sesuai dengan hasil penelitian Triana et al., (2007) yang menunjukkan bahwa semakin besar populasi ayam yang dipelihara, maka pendapatan yang diperoleh relatif besar pula, demikian juga dengan biaya produksi yang dikeluarkan. Hasil penelitian Fitriza et al., (2012) menunjukkan bahwa jumlah ternak yang dipelihara akan mempengaruhi besarnya pendapatan yang diperoleh oleh peternak, semakin banyak ayam yang dipelihara, maka semakin tinggi pendapatan yang diperoleh peternak.

Berdasarkan one sample t-test dengan menggunakan SPSS diketahui bahwa perbandingan pendapatan bersih per bulan dengan upah minimum Kabupaten (UMK) Semarang mencapai taraf signifikasi 0,015. Artinya adalah $\mathrm{H}_{0}$ ditolak dan $\mathrm{H}_{1}$ diterima karena nilai signifikansi $\leq 0,05$. Dengan demikian pendapatan bersih per bulan usaha ayam petelur pada peternakan Suyatno Farm lebih besar dan berbeda nyata dari UMK Kabupaten Semarang. Dengan demikian dapat disimpulkan bahwa skala populasi yang tinggi akan meningkatkan jumlah penerimaan dan mampu menghasilkan nilai pendapatan yang juga tinggi. Menurut Hasil penelitian Parasdya et al., (2013) menunjukkan bahwa jumlah ternak yang dipelihara akan mempengaruhi besarnya pendapatan yang diperoleh oleh peternak, semakin banyak ayam yang dipelihara, maka semakin tinggi pendapatan yang diperoleh peternak.

\section{KESIMPULAN DAN SARAN}

\section{Kesimpulan}

Usaha ayam petelur Suyatno Farm selama kurun waktu 2011 hingga 2013 mengalami fluktuasi biaya produksi dengan 14,73 dan $9,12 \%$. Pendapatan bersih usaha ayam petelur Suyatno Farm setelah pajak pada tahun 2011-2013 mencapai Rp 918.452.619; Rp 639.422.140 dan Rp 654.022.193.

\section{Saran}

Keuntungan perbulan peternakan Suyatno Farm lebih tinggi dibanding UMK Kabupaten Semarang, sehingga usaha peternakan layak untuk dijalankan di Kabupaten Semarang.

\section{DAFTAR PUSTAKA}

Dewanti, R. dan G. Sihombing. Analisis pendapatan usaha peternakan ayam buras (studi kasus di Kecamatan Tegalombo, Kabupaten Pacitan). Bulletin Peternakan 36(1):48-56.

Fenita, Y. 2011. Analisis faktor-faktor pengelolaan manajemen usaha peternakan ayam ras petelur di Kabupaten 50 Kota Provinsi Sumatera Barat. Agrisep 10(2):225241.

Fitriza, Y. T., F. T. Haryadi, dan S. P. Syahlani. 2012. Analisis pendapatan dan persepsi peternak plasma terhadap kontrak perjanjian pola kemitraan ayam petelur di Provinsi Lampung. Buletin Peternakan. 36 (1) : 57-65.

Management Guide of Isa Brown Layer. 2011.

Mulyani, A. dan R. Satriani. 2013. Kelayakan usaha peternakan ayam petelur kelompok wanita tani ternak "wanita karya" Kabupaten 
Banyumas. Jurnal Pembangunan Pedesaan 13(2):89-96.

Parasdya W., S. Mastuti dan O. E. Djatmiko. 2013. Analisis finansial usaha peternakan ayam niaga petelur di Kecamatan Kademangan Kabupaten Blitar. Jurnal Ilmiah Peternakan 1(1):88-98.

Peraturan Menteri Pertanian Republik Indonesia Nomor 31/Permentan/OT.140/2/2014.

Tentang Pedoman Budi Daya Ayam Pedaging Dan Ayam Petelur Yang Baik.

Rasyaf, M. 2009. Panduan Beternak Ayam Petelur. Penebar Swadaya, Jakarta.

Triana, A., T. Salam, dan M. Muis. 2007. Analisis pendapatan usaha peternakan ayam ras petelur periode layer di Kecamatan Cenrana Kabupaten Maros. Jurnal Agrisistem. 3(1): 11-15. 